\title{
INSTABILIDADE POSTURAL EM IDOSOS DURANTE A HOSPITALIZAÇÃO - REVISÃO DE LITERATURA
}

\section{INSTABILITY POSTURAL IN ELDERLY DURING HOSPITALIZATION - LITERATURE REVIEW}

\author{
Ana Paula de Jesus Conceição*, Emmanuelle Melo Sarraf**, Igor de Matos Pinheiro*** \\ Autora para correspondência: Emmanuelle Melo Sarraf - manusarraf@hotmail.com \\ *Fisioterapeuta das Obras Sociais Irmã Dulce (OSID) \\ **Fisioterapeuta Residente do Hospital Universitário Professor Edgar Santos (HUPES) \\ ***Mestre em Processos Interativos dos Órgãos e Sistemas - UFBA. Especialista em Reabilitação Neurofuncional \\ - FSBA
}

\section{R E S U M O}

Objetivo: Este estudo objetivou revisar a literatura para compreender a instabilidade postural em idosos durante hospitalização. $O$ envelhecimento por meio das implicações fisiológicas e patológicas pode resultar no surgimento das síndromes geriátricas, na qual a instabilidade postural pode desencadear complicações para a saúde do idoso. Materiais e Métodos: artigos que abordassem sobre a instabilidade postural em idosos durante a hospitalização e publicados entre 2001 a 2015 foram incluídos no estudo. Excluíram-se aqueles que abordaram a instabilidade postural associada a outras doenças. Resultados: 14 artigos fizeram parte do estudo, sendo a maioria referente às alterações posturais que podem influenciar nas atividades de vida diária. Idosos que permanecem por tempo indeterminado internados em uma unidade hospitalar estão mais susceptíveis a diversas alterações motoras e cognitivas, além de gerar custos e tempo prolongado na instituição. A instabilidade postural pode aumentar o risco de ocorrer quedas e interfere no desempenho funcional dos idosos. A restrição da mobilidade física resulta em enrijecimento das articulações, perda de estruturas ósseas e presença de patologias agudas ou crônicas. $O$ uso de medicamentos também interfere no controle postural dos idosos hospitalizados, provocam reações adversas, alterações cognitivas e motoras. Considerações Finais: Por conta da escassez de ensaios clínicos que envolvam o tema novos estudos são necessários para fundamentar e compreender a instabilidade postural em idosos durante hospitalização.

Palavras-chave: Equilíbrio postural, idoso e assistência a idosos. 
This study aimed to review the literature to understand the postural instability in the elderly during hospitalization. Aging through physiological and pathological implications may result in the emergence of geriatric syndromes in which postural instability may trigger complications to the health of the elderly. Articles that focused on postural instability in the elderly during hospitalization and published between 2001-2015 were included in the study. They excluded those who addressed the postural instability associated with other diseases. 14 articles were included in the study, mostly related to postural changes that may influence the activities of daily living. Seniors who remain indefinitely interned in a hospital are more susceptible to various motor and cognitive changes, and generate costs and extended time in the institution. Postural instability can increase the risk of falls occur and interfere with the functional performance of the elderly. Physical mobility restriction results in stiffening of the joints, loss of bone structures and the presence of acute or chronic diseases. The use of drugs also interferes with the postural control of the hospitalized elderly, cause adverse reactions, cognitive and motor changes. Because of the lack of clinical trials involving the issue further studies are needed to support and understand the postural instability in the elderly during hospitalization.

Keywords: Postural balance, aged and old age assistance. 


\section{INTRODUÇÃO}

O Brasil vive, nos últimos anos, uma mudança no seu perfil demográfico no qual tem resultado no crescimento do número de idosos. Estima-se que no ano de 2020 a população brasileira será a sexta maior no número de idosos, com cerca de 32 milhões de pessoas'. Devido a essa alteração no perfil populacional é necessário estudar as demandas sociais principalmente aquelas ligadas à saúde com objetivo de planejar e promover ações de assistência voltadas às necessidades dessa população².

Além do aumento do número da população idosa também se observa o crescimento de doenças associadas ao envelhecimento ${ }^{3}$, entre elas podemos citar as síndromes geriátricas: insuficiência cerebral; instabilidade postural; imobilidade; incapacidade comunicativa, insuficiência familiar, incontinência e iatrogenia ${ }^{2}$. As síndromes geriátricas levam o organismo do idoso a um processo de declínio fisiológico e podem acarretar mudanças estruturais e funcionais e comprometer $\circ$ desempenho das atividades motoras ${ }^{4,5}$.
A instabilidade postural na vida dos idosos interfere na deambulação, risco de queda, imobilidade, baixa da autoestima, aumento do medo e insegurança ${ }^{6}$. A diminuição gradual da capacidade funcional possibilita o idoso ser o maior consumidor dos serviços de saúde, devido às condições crônicas. Estes indivíduos apresentam maiores taxas de internação hospitalar e permanência prolongada nestes ambientes, sendo maioria nestes serviços quando comparado às outras faixas etárias ${ }^{7}$.

A hospitalização pode ser considerada um amplo fator de risco para o declínio funcional dos idosos. O internamento prolongado pode viabilizar complicações, gerar maiores custos financeiros, interferindo na qualidade de vida, além de poder levar a frequentes reinternarções ${ }^{8}$. Diante destas questões, este estudo objetivou revisar a literatura para compreender a instabilidade postural em idosos durante hospitalização.

\section{MATERIAIS E MÉTODOS}

A pesquisa da literatura foi realizada nas bases de dados eletrônicas: Biblioteca Virtual em Saúde (BVS), Medical Literature Analysis and Retrieval System Online (Medline), Scientific Eletronic Library Online (Scielo). Utilizaram-se as seguintes palavras-chave: Equilíbrio postural, idoso e assistência a idosos definidos com base no DeCS (Descritores em Ciências da Saúde). Artigos que abordassem sobre a instabilidade postural em idosos durante a hospitalização e publicados entre 2001 a 2015 foram incluídos no estudo. Excluíram-se aqueles que abordaram a instabilidade postural associada a outras patologias.

\section{RESULTADOS}

Pelo cruzamento das palavras-chave 25 artigos foram encontrados, destes 11 estudos considerados relevantes à revisão. Apenas três artigos apresentam o tempo de internação dos idosos hospitalizados com instabilidade postural, Tabela 1. Os idosos permanecem por tempo indeterminado internados na unidade hospitalar devido à instabilidade postural, estando susceptíveis a diversas alterações motoras e cognitivas que impactam diretamente no desempenho funcional para a execução das atividades de vida diária desta população, além de gerar maiores custos financeiros e tempo prolongado na instituição em que os mesmos permanecem. 
Tabela 1. Estudos que abordam o tempo de internação e aumento de custo dos idosos hospitalizados.

\begin{tabular}{|c|c|c|c|c|c|}
\hline Autor/Ano & Objetivo & Participantes & $\begin{array}{l}\text { Delineamento } \\
\text { do Estudo }\end{array}$ & Métodos & Resultados \\
\hline Pedrosa IL, 2014. & $\begin{array}{l}\text { Construir um } \\
\text { instrumento } \\
\text { de avaliação } \\
\text { prognóstica para } \\
\text { idosos internados } \\
\text { em unidade de } \\
\text { terapia intensiva. }\end{array}$ & $\begin{array}{c}205 \text { idosos, com } \\
\text { média de idade } \\
\text { de } 74,6 \text { anos e } \\
\text { mortalidade de } \\
59 \% \text {, com idade } \geq \\
60 \text { anos. }\end{array}$ & $\begin{array}{c}\text { Coorte, } \\
\text { com coleta } \\
\text { prospectiva. }\end{array}$ & $\begin{array}{l}\text { O instrumento foi } \\
\text { construído a partir } \\
\text { do estudo piloto e } \\
\text { a escala de Katz. } \\
\text { Para a análise dos } \\
\text { dados utilizou-se o } \\
\text { programa SPSS, o } \\
\text { teste qui-quadrado } \\
\text { de Pearson e a } \\
\text { técnica de regressão } \\
\text { de Poisson. }\end{array}$ & $\begin{array}{c}\text { Para os indivíduos que ficaram internados na } \\
\text { UTI até } 10 \text { dias, a taxa de sobrevivência foi de } \\
69,8 \% \text {, caindo para } 46,6 \%, 22,4 \% \text { e } 10,7 \% \text {, } \\
\text { para os que permanecem até } 20,40 \text { e } 50 \text { dias, } \\
\text { respectivamente. }\end{array}$ \\
\hline $\begin{array}{l}\text { Lira LN et al, } \\
2013 .\end{array}$ & $\begin{array}{l}\text { Aplicar histórico } \\
\text { de enfermagem } \\
\text { ao idoso } \\
\text { hospitalizado. }\end{array}$ & $\begin{array}{l}50 \text { idosos } \\
\text { hospitalizados } \\
\text { apresentando } 60 \\
\text { anos ou mais. }\end{array}$ & $\begin{array}{l}\text { Quantitativo } \\
\text { descritivo. }\end{array}$ & $\begin{array}{l}\text { Foi utilizado } \\
\text { instrumento de } \\
\text { coleta de dados, } \\
\text { denominado histórico } \\
\text { de enfermagem, } \\
\text { construído e } \\
\text { validado por meio } \\
\text { de dissertação de } \\
\text { mestrado. }\end{array}$ & $\begin{array}{c}\text { Idosos na faixa etária entre } 60-69(44 \%) \text {, } \\
\text { mulheres }(56 \%) \text {, cognição preservada }(68 \%) \text {, } \\
\text { anorexia }(54 \%) \text {, alterações nas eliminações } \\
\text { intestinais }(62 \%) \text { e urinárias }(66 \%) \text {, alterações } \\
\text { visuais }(70 \%) \text { e auditivas }(60 \%) \text {. O idoso } \\
\text { consome mais serviços de saúde, as internações } \\
\text { hospitalares são mais frequentes e o tempo de } \\
\text { ocupação do leito é maior quando comparado a } \\
\text { outras faixas etárias. }\end{array}$ \\
\hline $\begin{array}{c}\text { Siqueira } A B \text { et al, } \\
2004 .\end{array}$ & $\begin{array}{l}\text { Descrever as } \\
\text { alterações da } \\
\text { capacidade } \\
\text { funcional de } \\
\text { idosos durante } \\
\text { a internação } \\
\text { hospitalar } \\
\text { e o grau de } \\
\text { associação } \\
\text { dessas alteraçães } \\
\text { na ocasião da } \\
\text { alta hospitalar } \\
\text { a variáveis } \\
\text { sociodemográficas } \\
\text { e clínicas. }\end{array}$ & $\begin{array}{l}94 \text { pacientes } \\
\text { internados em } \\
\text { enfermaria } \\
\text { geriátrica } \\
\text { gerontológica de } \\
\text { um hospital-escola } \\
\text { geral de grande } \\
\text { porte da cidade } \\
\text { de São Paulo. }\end{array}$ & $\begin{array}{c}\text { Clínico } \\
\text { observacional. }\end{array}$ & $\begin{array}{l}\text { A primeira avaliação } \\
\text { da capacidade } \\
\text { funcional dos idosos } \\
\text { foi realizada } \\
\text { em até } 24 \text { horas } \\
\text { da entrada do } \\
\text { paciente e a última, } \\
\text { imediatamente após } \\
\text { a alta. Os pacientes } \\
\text { sofreram intervenções } \\
\text { terapêuticas } \\
\text { rotineiras por equipe } \\
\text { interdisciplinar. } \\
\text { Os dados foram } \\
\text { analisados pelo teste } \\
\text { qui-quadrado. }\end{array}$ & $\begin{array}{l}25,6 \% \text { obtiveram melhora na capacidade } \\
\text { funcional, } 34 \% \text { não sofreram alterações } \\
\text { funcionais, } 19,1 \% \text { pioraram funcionalmente e } \\
21,3 \% \text { faleceram durante o período. Houve } \\
\text { correlação significante entre a piora funcional } \\
\text { e a presença déficit cognitivo, delirium e baixa } \\
\text { capacidade funcional na entrada no hospital. }\end{array}$ \\
\hline
\end{tabular}

Na Tabela 2 são apresentados nove artigos que abordam o impacto da instabilidade postural para quedas em idosos hospitalizados. O equilíbrio, controle postural e a coordenação correspondem à base de sustentação do indivíduo e, quando alterados, podem ocorrer quedas que interferem no desempenho postural e da marcha dos idosos.

Tabela 2. Estudos que abordam a instabilidade postural e o impacto de quedas em idosos.

\begin{tabular}{|c|c|c|c|c|c|}
\hline Autor/Ano & Objetivo & Participantes & $\begin{array}{c}\text { Delineamento } \\
\text { do Estudo }\end{array}$ & Métodos & Resultados \\
\hline $\begin{array}{c}\text { Prates CG et al, } \\
2014 .\end{array}$ & $\begin{array}{l}\text { Identificar a } \\
\text { incidência e as } \\
\text { características } \\
\text { das quedas de } \\
\text { pacientes adultos } \\
\text { hospitalizados } \\
\text { em unidades de } \\
\text { internação (Uls) } \\
\text { clínico-cirúrgicas } \\
\text { e em atendimento } \\
\text { no serviço de } \\
\text { emergência (SE). }\end{array}$ & $\begin{array}{c}296 \text { leitos de } \\
\text { internação, onde } \\
\text { são realizadas, } \\
\text { em média } \\
1.800 \text { cirurgias } \\
\text { mensalmente, } \\
2.200 \\
\text { atendimentos no SE } \\
\text { e admitidos } 1.100 \\
\text { pacientes. }\end{array}$ & Retrospectivo. & $\begin{array}{c}\text { Os dados } \\
\text { foram coletados } \\
\text { retrospectivamente } \\
\text { a partir das } \\
\text { informações obtidas } \\
\text { no instrumento de } \\
\text { investigação de } \\
\text { quedas elaborado } \\
\text { pelo Grupo de } \\
\text { Prevenção de Quedas } \\
\text { (GPQ) e } \\
\text { no prontuário } \\
\text { eletrônico do sistema } \\
\text { informatizado TASY. }\end{array}$ & $\begin{array}{l}\text { A incidência foi de } 1,7 \text { para cada } 1.000 \\
\text { pacientes-dia nas UI's e } 2,6 \text { para cada } 1.000 \\
\text { internações no SE. A maioria ocorreu à noite } \\
(50,6 \%) \text {, no quarto do paciente }(65,4 \%) \text { e } \\
\text { da própria altura }(52,4 \%) \text {. Dos pacientes } \\
\text { que caíram } 90,8 \% \text { tinham risco para queda } \\
\text { pré-determinado, sendo a idade }(\geq 65) \\
\text { o principal fator. Das lesões decorrentes, } \\
82,6 \% \text { apresentaram dano leve e } 14 \text { desses } \\
\text { casos influenciaram no aumento do tempo de } \\
\text { permanência hospitalar. }\end{array}$ \\
\hline
\end{tabular}


(continuação)

\begin{tabular}{|c|c|c|c|c|c|}
\hline Autor/Ano & Objetivo & Participantes & $\begin{array}{c}\text { Delineamento } \\
\text { do Estudo }\end{array}$ & Métodos & Resultados \\
\hline $\begin{array}{l}\text { Silva A et al., } \\
2012 .\end{array}$ & $\begin{array}{l}\text { Avaliar a } \\
\text { ocorrência } \\
\text { de quedas } \\
\text { e os fatores } \\
\text { associados como } \\
\text { sua frequência, e } \\
\text { a relação entre } \\
\text { mobilidade e } \\
\text { funcionalidade. }\end{array}$ & $\begin{array}{l}205 \text { idosos de } \\
\text { etnias negra, } \\
\text { branca, parda ou } \\
\text { amarela, } \\
\text { autodefinida pelo } \\
\text { entrevistado, } \\
\text { durante } \\
\text { questionário que } \\
\text { abordou aspectos } \\
\text { sociodemográ- } \\
\text { ficos, } \\
\text { socioeconômi- } \\
\text { cos, assim como } \\
\text { questões sobre } \\
\text { quedas. }\end{array}$ & $\begin{array}{l}\text { Transversal } \\
\text { analítico. }\end{array}$ & $\begin{array}{l}\text { A avaliação geral } \\
\text { consistiu em analisar } \\
\text { condições socioeconô- } \\
\text { micas e demográficas } \\
\text { e clínico-funcionais. } \\
\text { Informações sobre } \\
\text { quedas foram obtidas } \\
\text { através de questio- } \\
\text { nário com respostas } \\
\text { de múltipla escolha } \\
\text { desenvolvido pelo } \\
\text { pesquisador principal } \\
\text { com embasamento } \\
\text { na literatura a fim } \\
\text { de trazer ao estudo } \\
\text { maior grau de especi- } \\
\text { ficidade. }\end{array}$ & $\begin{array}{c}\text { Amostra de } 196 \text { idosos sendo } 48,5 \% \text { brancos, } \\
28 \% \text { pardos, } 23,5 \% \text { negros. Média de } 69,9 \\
\text { anos. Mobilidade reduzida classificando médio } \\
\text { risco a quedas para } 60 \% \text { ( } p<0,013 \text { ) dos } \\
\text { idosos. }\end{array}$ \\
\hline $\begin{array}{c}\text { Antes DL et al, } \\
2014 .\end{array}$ & $\begin{array}{l}\text { Verificar a } \\
\text { estabilidade } \\
\text { postural e a } \\
\text { propriocepção } \\
\text { de idosas } \\
\text { praticantes de } \\
\text { hidroginástica. }\end{array}$ & $\begin{array}{l}25 \text { idosas com } \\
\text { idade média de } \\
70,2 \text { (de 6,9) } \\
\text { anos, praticantes } \\
\text { de hidroginástica } \\
\text { de intensidade } \\
\text { moderada há no } \\
\text { mínimo três meses } \\
\text { e com duas aulas } \\
\text { semanais. }\end{array}$ & $\begin{array}{l}\text { Descritivo- } \\
\text { correlacional. }\end{array}$ & $\begin{array}{l}\text { Para testar a proprio- } \\
\text { cepção, utilizou-se o } \\
\text { goniômetro analógico } \\
\text { fixo, assentado no } \\
\text { membro inferior pre- } \\
\text { ferido do sujeito. A es- } \\
\text { tabilidade postural foi } \\
\text { analisada utilizando } \\
\text { uma plataforma de } \\
\text { força no nível do solo. }\end{array}$ & $\begin{array}{l}\text { A propriocepção apresentou correlação } \\
\text { positiva }(R=0,551 ; p=0,004) \text { com a idade } \\
\text { e com a estabilidade postural, na condição de } \\
\text { OA e OF, apresentando maiores amplitudes e } \\
\text { velocidades de deslocamento do } \\
\qquad P(p<0,05) .\end{array}$ \\
\hline $\begin{array}{c}\text { Aikawa AC et } \\
\text { al, } 2006 .\end{array}$ & $\begin{array}{l}\text { Estudar a } \\
\text { associação entre } \\
\text { as adaptações } \\
\text { posturais, } \\
\text { oscilações } \\
\text { posturais, índice } \\
\text { de quedas e } \\
\text { idade. }\end{array}$ & $\begin{array}{c}16 \text { idosos } \\
\text { de ambos } \\
\text { os gêneros, } \\
\text { masculino }(n=5) \text { e } \\
\text { feminino }(n=11) \text {, } \\
\text { divididos em } \\
\text { grupos segundo a } \\
\text { faixa etária: de } \\
60 \text { a } 70 \text { anos e } \\
\text { de } 71 \text { a } 80 \text { anos } \\
\text { de idade. }\end{array}$ & Descritivo. & $\begin{array}{l}\text { Os dados foram obti- } \\
\text { dos por meio de uma } \\
\text { avaliação postural e } \\
\text { a análise da oscilação } \\
\text { anterior e posterior } \\
\text { por meio de fotogra- } \\
\text { metria computadori- } \\
\text { zada. A existência de } \\
\text { associação entre as } \\
\text { oscilações, índice de } \\
\text { quedas e o avanço } \\
\text { da idade foi avaliada } \\
\text { pelo } \chi 2 \text { ( } \mathrm{p} \leq 0.05 \text { ) }\end{array}$ & $\begin{array}{c}\text { Os graus de oscilações posturais ântero- } \\
\text { posteriores para indivíduos que relataram } \\
\text { quedas no último ano foram 12,2\% (60-70 } \\
\text { anos) e } 69,2 \% \text { ( } 71-80 \text { anos) maiores do } \\
\text { que os indivíduos que não apresentaram } \\
\text { quedas. O teste estatístico apontou diferenças } \\
\text { significativas nos graus de oscilações com } \\
\text { relação ao índice de quedas e em função da } \\
\text { idade. }\end{array}$ \\
\hline $\begin{array}{c}\text { Sousa RM et al, } \\
2010 .\end{array}$ & $\begin{array}{l}\text { Identificar e } \\
\text { analisar os } \\
\text { diagnósticos de } \\
\text { enfermagem } \\
\text { associados } \\
\text { à presença } \\
\text { das síndromes } \\
\text { geriátricas } \\
\text { em idosos } \\
\text { hospitalizados. }\end{array}$ & $\begin{array}{l}66 \text { pessoas com } \\
\text { mais de } 65 \text { anos, } \\
\text { internadas nas } \\
\text { unidades clínicas } \\
\text { e cirúrgicas } \\
\text { do Hospital } \\
\text { Universitário } \\
\text { Antonio Pedro, } \\
\text { Niterói-RJ, Brasil. }\end{array}$ & Quantitativo. & $\begin{array}{l}\text { Utilizando-se } \\
\text { das técnicas de } \\
\text { pesquisa, entrevista } \\
\text { semiestruturada e } \\
\text { formulários específicos } \\
\text { da gerontologia. }\end{array}$ & $\begin{array}{l}\text { Identificaram } 394 \text { diagnósticos de enfermagem } \\
\text { correlacionados às cinco principais síndromes } \\
\text { geriátricas, Isolamento social } 129(32,8 \%) \text {, } \\
\text { latrogenia } 113(28,6 \%) \text {, Instabilidade postural } \\
81(20,6 \%) \text {, Insuficiência cerebral } 44(11,1 \%) \\
\text { e Incontinência urinária } 27(6,9 \%) \text {. }\end{array}$ \\
\hline $\begin{array}{c}\text { Moraes EN et } \\
\text { al, } 2010 .\end{array}$ & $\begin{array}{c}\text { Realizar a } \\
\text { avaliação } \\
\text { multidimensional } \\
\text { e a identificação } \\
\text { e tratamento } \\
\text { das síndromes } \\
\text { geriátricas, } \\
\text { principais } \\
\text { responsáveis pela } \\
\text { perda da sua } \\
\text { autonomia e } \\
\text { independência. }\end{array}$ & ----- & Revisão. & $\begin{array}{l}\text { Análise das atividades } \\
\text { de vida diária, } \\
\text { que são tarefas do } \\
\text { cotidiano realizadas } \\
\text { pelo paciente. }\end{array}$ & $\begin{array}{l}\text { A saúde do idoso é determinada pelo } \\
\text { funcionamento harmonioso de quatro domínios } \\
\text { funcionais: cognição, humor, mobilidade e } \\
\text { comunicação. }\end{array}$ \\
\hline
\end{tabular}


(continuação)

\begin{tabular}{|c|c|c|c|c|c|}
\hline Autor/Ano & Objetivo & Participantes & $\begin{array}{c}\text { Delineamento } \\
\text { do Estudo }\end{array}$ & Métodos & Resultados \\
\hline $\begin{array}{l}\text { Fabrício SCC } \\
\text { et al, } 2004 .\end{array}$ & $\begin{array}{l}\text { Investigar a } \\
\text { história da } \\
\text { queda relatada } \\
\text { por idosos, } \\
\text { identificando } \\
\text { fatores } \\
\text { possivelmente } \\
\text { relacionados, } \\
\text { assim como local } \\
\text { de ocorrência, } \\
\text { causas e } \\
\text { conseqüências. }\end{array}$ & $\begin{array}{l}50 \text { idosos, de } \\
\text { ambos os sexos, } \\
\text { com idade de } \\
60 \text { anos ou mais, } \\
\text { residentes em } \\
\text { Ribeirão Preto, } \\
\text { SP, que haviam } \\
\text { sido atendidos } \\
\text { em duas unidades } \\
\text { de um hospital } \\
\text { público. }\end{array}$ & Descritivo. & $\begin{array}{l}\text { Foram consultados } \\
\text { prontuários e } \\
\text { realizadas visitas } \\
\text { domiciliares para } \\
\text { aplicação de } \\
\text { um questionário } \\
\text { estruturado com } \\
\text { perguntas abertas, } \\
\text { fechadas e mistas } \\
\text { relativas à queda. }\end{array}$ & $\begin{array}{c}\text { A maioria das quedas ocorreu entre idosos } \\
\text { do sexo feminino ( } 66 \%) \text {, com idade média } \\
\text { de } 76 \text { anos, no próprio lar do idoso ( } 66 \%) \text {. } \\
\text { As causas foram principalmente relacionadas } \\
\text { ao ambiente físico ( } 54 \%) \text {, acarretando sérias } \\
\text { consequências aos idosos, sendo as fraturas as } \\
\text { mais freqüentes ( } 64 \% \text { ). }\end{array}$ \\
\hline $\begin{array}{l}\text { Dascal JB, } \\
2009 .\end{array}$ & $\begin{array}{l}\text { Determinar } \\
\text { se o sistema } \\
\text { háptico, durante } \\
\text { o uso de uma } \\
\text { ferramenta não } \\
\text { rígida, melhora } \\
\text { a estabilidade } \\
\text { postural nas } \\
\text { tarefas de } \\
\text { equilíbrio estático } \\
\text { em idosos. }\end{array}$ & $\begin{array}{l}30 \text { indivíduos } \\
\text { saudáveis } \\
\text { e ativos, } \\
\text { subdivididos em } \\
\text { dois grupos: Um } \\
\text { grupo idoso, } \\
\text { composto de } 15 \\
\text { idosos e um grupo } \\
\text { jovem, composto } \\
\text { de } 15 \text { adultos. }\end{array}$ & Descritivo. & $\begin{array}{l}\text { Todos os participantes } \\
\text { realizaram medidas } \\
\text { de antropometria } \\
\text { (peso e estatura) e } \\
\text { foram convidados } \\
\text { a responder } \\
\text { um questionário } \\
\text { relacionado à } \\
\text { quantidade de } \\
\text { atividades motoras } \\
\text { realizadas no } \\
\text { cotidiano. }\end{array}$ & $\begin{array}{l}\text { O grupo de idosos apresentou maior oscilação } \\
\text { corporal que o grupo de adultos jovens, nas } \\
\text { duas condições visuais investigadas; que a } \\
\text { ausência da informação visual provocou maior } \\
\text { instabilidade postural para ambos os grupos e } \\
\text { que o sistema âncora foi útil para estabilizar a } \\
\text { postura dos dois grupos estudados, }\end{array}$ \\
\hline $\begin{array}{c}\text { Santos FPV et } \\
\text { al, } 2013 .\end{array}$ & $\begin{array}{l}\text { Analisar a } \\
\text { correlação } \\
\text { entre três testes } \\
\text { utilizados para } \\
\text { avaliar o risco } \\
\text { de quedas em } \\
\text { idosos. }\end{array}$ & $\begin{array}{l}49 \text { idosos } \\
\text { comunitários, } \\
\text { hígidos, com } \\
\text { diferentes } \\
\text { níveis de } \\
\text { condicionamento } \\
\text { físico. }\end{array}$ & $\begin{array}{c}\text { Transversal } \\
\text { analítico. }\end{array}$ & $\begin{array}{l}\text { Foram utilizados dois } \\
\text { testes clínicos, o Timed } \\
\text { Up and Go (TUG) e o } \\
\text { QuickScreen Clinical } \\
\text { Fall Risck Assessment } \\
\text { (QuickScreen), e } \\
\text { um laboratorial, } \\
\text { o Biodex Balance } \\
\text { System - Modo Fall } \\
\text { Risck (BBS-FR). A } \\
\text { correlação dos dados } \\
\text { foi realizada por } \\
\text { meio da aplicação } \\
\text { do coeficiente de } \\
\text { correlação de } \\
\text { Spearman. }\end{array}$ & $\begin{array}{l}\text { A maioria dos idosos dos grupos etários de } \\
60-71 \text { anos de idade ( } n=30 \text { ) e } 72-89 \text { anos } \\
\text { ( } n=11 \text { ) não apresentou oscilação corporal } \\
\text { maior ou igual a } 3,7 \text { graus para o primeiro } \\
\text { grupo, e } 4,0 \text { graus para o segundo grupo. } \\
\text { Isso indica que a maioria dos participantes } \\
\text { não possui risco de quedas aumentado para } \\
\text { as faixas etárias estudadas, segundo os } \\
\text { critérios do instrumento. Os resultados do } \\
\text { teste QuickScreen revelam que a amostra } \\
\text { apresentou, em média, até um fator de risco } \\
\text { para quedas, o que resultou em índice de } \\
\text { queda médio aumentado de } 1,76 \text { ( } \pm 1,86 \text { ) em } \\
\text { relação a idosos que não apresentam nenhum } \\
\text { fator de risco. }\end{array}$ \\
\hline
\end{tabular}

Na Tabela 3 um artigo apresenta a mobilidade física como uma restrição ao movimento físico independente e voluntário do corpo ou de uma ou mais extremidades. $O$ possível desenvolvimento de conflitos posturais secundários a instabilidade postural, influência no desempenho das atividades da vida diária que pode levar a déficits cognitivos, nutricionais, articulares e estruturais e culminar em doenças agudas ou crônicas degenerativas.

Tabela 3. Estudo que aborda a mobilidade física como uma restrição no movimento físico independente e voluntário.

\begin{tabular}{|c|c|c|c|c|c|}
\hline Autor/Ano & Objetivo & Participantes & $\begin{array}{c}\text { Delineamento } \\
\text { do Estudo }\end{array}$ & Métodos & Resultados \\
\hline $\begin{array}{c}\text { Sakano LM, } \\
\text { Yoshitome AY, } \\
2007 .\end{array}$ & $\begin{array}{l}\text { Conhecer os } \\
\text { principais } \\
\text { diagnósticos de } \\
\text { enfermagem } \\
\text { (DE) em idosos } \\
\text { e propor as } \\
\text { intervenções de } \\
\text { enfermagem. }\end{array}$ & $\begin{array}{c}\text { A população } \\
\text { do estudo foi } \\
\text { composta pelas } \\
61 \text { fichas da SAE } \\
\text { para idosos e que } \\
\text { foram preenchida } \\
\text { no período de } \\
\text { junho a dezembro } \\
\text { de } 2000 \text {. }\end{array}$ & Retrospectivo. & $\begin{array}{c}\text { Realizado na } \\
\text { enfermaria de } \\
\text { geriatria de um } \\
\text { hospital universitário } \\
\text { da cidade de São } \\
\text { Paulo. }\end{array}$ & $\begin{array}{c}\text { Risco para infecção ( } 100 \%) \text {, mobilidade física } \\
\text { prejudicada }(50,7 \%) \text {, nutrição alterada: menos } \\
\text { que as necessidades corpóreas }(44,7 \%) \text {, déficit } \\
\text { no autocuidado }(43,3 \%) \text {, integridade da pele } \\
\text { prejudicada }(41,8 \%) \text {. }\end{array}$ \\
\hline
\end{tabular}


Na Tabela 4 um artigo retrata as reações adversas ao uso de medicamentos. $O$ uso de remédios pode influenciar no controle postural dos idosos hospitalizados. Dentre as reações adversas, observam-se as alterações cognitivas e motoras que podem aumentar os riscos à saúde do idoso, induzem ao prolongamento da hospitalização e gera custos deixando o idoso susceptível ao óbito.

Tabela 4. Estudo que aborda às reações adversas ao uso de medicamentos.

\begin{tabular}{|c|c|c|c|c|c|}
\hline Autor/Ano & Objetivo & Participantes & $\begin{array}{c}\text { Delineamento } \\
\text { do Estudo }\end{array}$ & Métodos & Resultados \\
\hline $\begin{array}{c}\text { Passarelli MCG, } \\
\text { Jacob Filho W, } \\
2007 .\end{array}$ & $\begin{array}{l}\text { Determinar os } \\
\text { fatores de risco } \\
\text { para reação } \\
\text { adversa ao uso de } \\
\text { medicamentos em } \\
\text { uma população } \\
\text { idosa. }\end{array}$ & $\begin{array}{c}186 \text { idosos ( } \geq 60 \\
\text { anos) internados } \\
\text { na enfermaria de } \\
\text { clínica médica de } \\
\text { um hospital-escola. }\end{array}$ & Descritivo. & $\begin{array}{l}\text { Avaliados diariamente } \\
\text { para pesquisa e } \\
\text { diagnóstico de } \\
\text { Reação Adversa } \\
\text { ao Medicamento. } \\
\text { Os fatores de risco } \\
\text { associados obtidos } \\
\text { por um modelo de } \\
\text { regressão logística } \\
\text { múltipla e adotou-se } \\
\text { o método de seleção } \\
\text { de variáveis backward } \\
\text { para a criação de um } \\
\text { Instrumento de Previsão } \\
\text { de Reação adversa ao } \\
\text { medicamento. }\end{array}$ & $\begin{array}{c}115 \text { pacientes (61,8\%) apresentaram no mínimo } \\
\text { uma RAM, } 91 \% \text { das quais do tipo A. Os fatores } \\
\text { de risco considerados significativos para Reação } \\
\text { Adversa ao Medicamento foram o número de } \\
\text { diagnósticos (OR }=1,41 \text {; IC } 95 \%[1,06-1,86]) \text {, } \\
\text { o número de medicamentos (OR }=1,10 ; \text { IC } \\
95 \%[1,03-1,17]) \text { e o uso de medicamento } \\
\text { inapropriado para idosos (OR = 2,32; IC } 95 \% \\
[1,17-4,58]) \text {. }\end{array}$ \\
\hline
\end{tabular}

A maioria dos estudos refere que as alterações posturais podem influenciar nas atividades de vida diária e aumentar os índices de mortalidade, porém ainda é controverso na literatura se o tipo de internação e fatores ligados à clínica do paciente influência nas alterações posturais.

\section{DISCUSSÃO}

A análise da literatura evidenciou que a instabilidade postural em idosos durante a hospitalização está relacionada com as alterações fisiológicas, cognitivas e funcionais do envelhecimento. $O$ indivíduo idoso hospitalizado está vulnerável às alterações clínicas que comprometem o desempenho, pode proporcionar maior tempo e aumento de custo nas internações. A instabilidade postural está diretamente ligada à ocorrência de quedas, restrição da mobilidade física e às reações adversas com o uso de medicamentos, fatores estes que podem ocasionar ao óbito.

O percentual do número de idosos tem aumentado ao longo dos anos na população brasileira ${ }^{9}$ devido ao aumento da expectativa de vida, redução da taxa de nascimento e mortalidade 9,10 . Com $\circ$ aumento da longevidade, houve também o crescimento da incidência de patologias crônico-degenerativas, neurológicas e musculoesqueléticas que podem levar a redução da autonomia e independência com consequente redução da capacidade funcional ${ }^{10}$.
As implicações fisiológicas e patológicas do envelhecimento, quando descuidados cooperam no surgimento das grandes síndromes geriátricas. Segundo Moraes et al, as síndromes geriátricas são: Insuficiência Cerebral, Instabilidade Postural, Imobilidade, Incapacidade Comunicativa, Insuficiência Familiar, Incontinência e latrogenia ${ }^{1}$.

No estudo de Souza et $a l^{6}$ estes afirmam que essas síndromes desencadeiam uma maior fragilidade dos idosos que podem levar a uma série de complicações e a dependência funcional.6 Isso fica mais evidente nos pacientes hospitalizados, pois muitas das vezes, mesmo depois da alta hospitalar, essas síndromes não são completamente revertidas o que aumentam as taxas de reinternações, alto custo e complicações ${ }^{6}$. Por isso é indispensável compreender o problema dessas síndromes no ambiente hospitalar e suas implicações ${ }^{6}$.

O envelhecimento diminui a capacidade de 
manutenção de várias funções corporais entre elas podemos citar as alterações de equilíbrio ${ }^{12}$. A redução da qualidade na resposta proprioceptiva leva a disfunções no controle corporal que podem gerar instabilidades posturais e aumentar o risco de quedas ${ }^{13}$ que resultam no aumento das taxas de admissão nos serviços de saúde no qual pode chegar até 20 mil internações por ano em alguns países $^{10}$. Essas alterações posturais modificam - deslocamento do centro da gravidade em relação à base de sustentação e irá ocasionar uma falha na manutenção da estabilidade que se agrava à medida que se aumenta a idade ${ }^{14}$. $O$ equilíbrio postural depende do funcionamento e da integração dos sistemas: nervoso, central, sensorial, osteoarticular e do estado hemodinâmico ${ }^{15}$. Para se avaliar o controle postural é necessário observar as oscilações corporais, pois mesmo em pequeno limiar e em uma postura quieta o nosso sistema postural está em movimentação constante.

Durante o envelhecimento esses mecanismos podem estar alterados e estes apresentam maior oscilação corporal, alterações na utilização das informações sensoriais e da ativação muscular para manter a posição do corpo na forma desejável o que implica em uma maior instabilidade postural comparado à população adulta ${ }^{15}$. Confirmando este achado um estudo verificou que o aumento da idade está relacionado com o aumento da instabilidade postural devido a vários fatores principalmente aqueles ligados à diminuição da força muscular, redução da velocidade na condução nervosa e associados aos declínios fisiológicos do envelhecimento ${ }^{13}$.

A mobilidade física é conceituada como uma restrição no movimento físico independente e voluntário do corpo de uma ou mais extremidades ${ }^{16}$. A instabilidade postural está relacionada a uma das principais desordens que afeta a vida dos idosos, pois leva a dificuldade na deambulação, aumenta - risco de queda, pode gerar imobilidade, baixa autoestima e desenvolver medo e insegurança ${ }^{6}$. A instabilidade postural influência na execução de atividades da vida diária pode limitar a amplitude de movimento, estar relacionada ao uso de medicações, causar desordens sensório-perceptivas, neuromusculares e musculoesqueléticas, levar a prejuízo cognitivo, má nutrição, enrijecimento das articulações e contraturas, perda da integridade de estruturas ósseas e presença de doenças agudas ou crônicas degenerativas ${ }^{6}$.

Para a população idosa a hospitalização pode levar ao agravamento das condições fisiológicas que o levaram ao internamento, devido situações que envolvem medo, insegurança e estresse ${ }^{12}$. $O$ idoso apresenta maior custo nos serviços de saúde como consequência das internações hospitalares frequentes e o longo período de permanência quando comparado às outras faixas etárias ${ }^{17}$. Em sua maioria, as patologias dos idosos são múltiplas e crônicas, no qual exigem acompanhamentos constantes como cuidados permanentes, exames e medicações contínuas. A permanência no hospital dependerá do tipo de doença, o estado geral, a resposta ao tratamento realizado e potenciais complicações existentes ${ }^{17}$. A hospitalização, muitas das vezes levam a alterações funcionais e mudanças na qualidade das atividades de vida diária que podem ser irreversíveis ${ }^{8}$.

Os indivíduos que estão internados nas unidades clinicas possuem maior probabilidade de desenvolver alterações posturais do que pacientes cirúrgicos pois estes apresentam maior tempo de internação, maior número de comorbidades e maior complexidade que fica mais evidente na população idosa $^{18}$. As principais patologias que acarretam efeitos sobre o equilíbrio postural são: doenças cardiovasculares, neurológicas, endocrinológicas, osteomusculares, geniturinária, psiquiátricas e sensoriais $^{19}$. Contestando essa informação foi realizado um estudo prospectivo no qual analisaram fatores de risco para a instabilidade postural como: risco para quedas, deambulação, mobilidade física prejudicada, insônia, intolerância a atividade, entre outros, no qual comparou os idosos internados na clínica médica e cirúrgica e verificaram que esta não é desencadeada por causa do tipo de internação, queixa principal ou fatores ligados a clínica do paciente $^{6}$.

Uso de fármacos também influência no controle postural $^{19}$. A terapia medicamentosa pode ser efetiva no controle da maioria das doenças porém, alguns fármacos, em maior ou menor proporção, podem propiciar uma reação adversa ${ }^{20}$. O idoso é o individuo mais vulnerável às reações adversas ao uso de medicamentos em virtude dos seguintes fatores: particularidades, presença de múltiplas doenças, o uso de números elevados de medicamentos e os tipos 
prescritos $^{20}$. Medicações como anti-hipertensivos, anti-parkinsonianos, diuréticos e psicotrópicos podem levar a alterações nas funções motoras com consequente fraqueza muscular, vertigem e hipotensão postural aumentando $\circ$ risco de quedas $^{19}$. A polifármacia principalmente em idosos que apresentam uma condição de saúde precária pode levar ao aumento desses fatores de risco ${ }^{20}$. Por isso é importante analisar criteriosamente a sua prescrição para que esses efeitos possam ser evitados, pois na população idosa essas reações medicamentosas podem prolongar o período de internação, custos e até levar a óbito ${ }^{20}$.

A equipe multiprofissional de saúde deve orientar, desenvolver e incentivar atividades que atenuem a correlação entre envelhecimento e redução da estabilidade postural ${ }^{13}$. A equipe pode atuar no estímulo a atividade física, nutrição adequada, observar a prescrição de medicamentos e corrigir os déficits sensoriais. Os idosos devem permanecer - menor tempo possível no leito ${ }^{6}$ especialmente aqueles portadores de múltiplas condições crônicas, pois seus problemas de saúde podem levar a limitações funcionais e consequentemente ao desenvolvimento de dependência nas atividades de vida diária após o momento da alta hospitalar. 8 O entendimento do funcionamento do controle postural, principalmente para a população idosa torna-se importante e urgente para que alternativas surjam a fim de minimizar complicações e consequentemente melhorar a qualidade de vida durante o envelhecimento.

Existe uma escassez de ensaios clínicos que envolvam a instabilidade postural em idosos hospitalizados, fato este que limita a exploração do tema abordado. Além disso, os poucos estudos presentes na literatura possuem baixo nível de evidência científica por não se tratarem de ensaios clínicos. Espera-se que, com a realização de novos estudos, a instabilidade postural na população estudada possa ser mais fundamentada.

\section{CONSIDERAÇÕES FINAIS}

A partir desta revisão bibliográfica, observou-se que o avançar da idade está relacionado com - aumento da instabilidade postural devido a associações de fatores ligados às alterações fisiológicas do envelhecimento. Esta síndrome geriátrica também pode influenciar na execução das atividades de vida diária. Idosos que permanecem por tempo indeterminado internados em uma unidade hospitalar estão mais susceptíveis a diversas alterações motoras e cognitivas, além de gerar custos e tempo prolongado na instituição. A instabilidade postural pode aumentar o risco de ocorrer quedas e interfere no desempenho funcional dos idosos. A restrição da mobilidade física resulta em enrijecimento das articulações, perda de estruturas ósseas e presença de doenças agudas ou crônicas degenerativas. $O$ uso de medicamentos também influência no controle postural dos idosos hospitalizados e possibilitam reações adversas como alteração do sistema cognitivo e motor.

\section{REFERÊNCIAS}

1. Loyola Al, Matos DL, Giatti L, Afradique ME, Peixoto SV, Costa MFL. Causas de internações hospitalares entre idosos brasileiros no âmbito do Sistema Único de Saúde. Epidemiologia e Serviços de Saúde. 2005;13(4):229-238. doi: 10.5123/ S1679-49742004000400005

2. Martin GB, Junior LC, Bastos YGL, Silva PV. Assistência hospitalar à população idosa em cidade do sul do Brasil. Epidemiologia e Serviços de Saúde. 2006;15(1):59-65. doi: 10.5123/ S1679-49742006000100005

3. Maciel ACC, Guerra RO. Prevalência e fatores associados ao déficit de equilíbrio em idosos. $R$. bras. Ci. e Mov. 2005; 13(1):37-44.

4. Rosa TSM, Moraes AB, Peripolli A, Santos VAV. Perfil epidemiológico de idosos que foram a óbito por queda no Rio Grande do Sul. Rev. Bras. Geriatr. Gerontol. 2015;18(1):59-69. doi: 10.1590/1809-9823.2015.14017

5. Melo SCB, Leal SMC, Vargas MAO. Internação de idosos por causas externas em um hospital 
público de trauma. Enfermagem em Foco. $2011 ; 2(4): 226-230$.

6. Souza RM, Santana RF, Espirito Santo $\mathrm{FH}$, Almeida JG, Alves LAF. Diagnósticos de enfermagem identificados em idosos hospitalizados: associação com as síndromes geriátricas. Esc Anna Nery. 2010;14(4):732-741. doi: $10.1590 /$ S1 $414-81452010000400012$

7. Silva TM, Nakatani AYK, Souza ACS, Lima ACS. A vulnerabilidade do idoso para as quedas: análise dos incidentes críticos. Rev. Eletrônica de Enfermagem. 2007;9(1):64-78.

8. Siqueira $A B$, Cordeiro $R C$, Perracini $M R$, Ramos LR. Impacto funcional da internação hospitalar de pacientes idosos. Rev. Saúde Pública. 2004;38(5):687-94. doi: 10.1590/s003489102004000500011

9. Santos FPV, Borges LL, Menezes RL. Correlação entre três instrumentos de avaliação para risco de quedas em idosos. Fisioter Mov. 2013;26(4):88394. doi: 10.1590/S0103-51502013000400017

10. Silva A, Faleiros HH, Shimizu WAL, Nogueira $L M$, Nhãn LL, Silva BMF et al. Prevalência de quedas e de fatores associados em idosos segundo etnia. Ciência \& Saúde Coletiva. 2012;17(8):2181-2190. doi: 10.1590/S141381232012000800028

11. Moraes EM, Marino MCA, Santos RR. Principais síndromes geriátricas. Rev Med. 2010;20(1):54-66.

12. Pedrosa IL. Construção de um instrumento de avaliação prognóstica para idosos em unidade de terapia intensiva. Revista Brasileira de Terapia Intensiva. 2014; (Supl1):S7-S43.

\section{Antes DL, Wiest MJ, Mota CB, Corazza ST.}

Análise da estabilidade postural e propriocepção de idosas fisicamente ativas. Fisioter Mov.

2014;27(4):531-9. doi: 10.1590/0103-

5150.027.004.AO05

14. Aikawa AC, Braccialli LMP, Padula RS. Efeitos das alterações posturais e de equilíbrio estático nas quedas de idosos institucionalizados. Rev.

Ciênc. Méd. 2006;15(3):189-196.
15. Dascal JB. Controle postural de idosos: efeito da perturbação visual com o uso do sistema âncora. Rio Claro: 2009.

16. Sakano LM, Yoshitome AY. Diagnósticos e intervenções de enfermagem em idosos hospitalizados. Acta Paul Enferm. 2007;20(4):4958. doi: $10.1590 /$ S0103-21002007000400018

17. Lira LN, Santos SSC, Gautério DP, Vidal DAS, Tier CG. Histórico de enfermagem para idosos hospitalizados: base para diagnósticos e prescrições. Rev enferm UFPE online. $2013 ; 7(8)$ : 5198-206. doi: 10.5205/revol.3452-28790-4

18. Prates CG, Luzia MF, Ortolan $M R$, Neves $C M$, Bueno ALM, Guimarães F. Quedas em adultos hospitalizados: incidência e características desses eventos. Cienc Cuid Saúde. 2014;13(1):74-81. doi: 10.4025 /cienccuidsaude.v13i1.20728

19. Fabrício SCC, Rodrigues RAP, Junior MLC. Causas e consequências de quedas de idosos atendidos em hospital público. Rev Saúde Pública. 2004;38(1):93-9. doi: 10.1590/S003489102004000100013

20. Passarelli MCG, Jacob Filho W. Reações adversas a medicamentos em idosos: como prevêlas? Einstein. 2007;5(3):246-251. 